\title{
A PROCESSÃO EM PLOTINO
}

Reinholdo Aloysio Ullmann*

SINTESE - Este artigo ocupa-se dos aspectos essenciais da processāo plotiniana, com base nas Enéadas e em intérpretes de projeção mundial, como Giovanni Reale e Werner Beierwaltes. A processão de Plotino trata da origem das coisas, a partir do Uno, o qual se identifica com Super-Ser, divino, eterno, perfeito e imutável, não podendo ser entendido como conceito abstrato universalíssimo. O trabalho pretende mostrar que Plotino não é emanatista, nem panteista, mas panenteísta. Há mesmo quem o considere criacionista. É abordada, especialmente, a paisagem metafísica de Plotino, com as três hipóstases do mundo inteligivel e, dependendo deste, a origem do mundo sensível - a matéria - tida pelo filósofo como principio do mal, porém não em sentido gnóstico-maniqueísta. Por fim, o artigo conclui que a processão implica, necessariamente, o retorno da alma humana ao Uno. O objetivo da filosofia plotiniana era levar os seus seguidores à união mais íntima possível com o Uno.
ABSTRACT - This article deals with the problem of the procession in Plotinus' Enneadae, whose influence on the later philosophy, specially in the Middle Ages, is undeniable. From the One, i.e., God, the Uper-Good, transcendent, eternal, unchangeable, proceeds by "emanation" the multiplicity of beings. This paper tries to show that the Roman philosopher, born in Egypt, neither was an emanatist in a strict sense nor a pantheist, but a panentheist. His metaphysics involves the famous triad or the three hypostases, also here briefly explained. According to Plotinus, the material world is the cause of the evil, understanding it as the last and the lowest limit of a possible existence. Finally, to the procession from the One corresponds the human effort for ascending to Him. In fact, the aim of Plotinus' philosophy was to lead his followers to the most intimate union with the One.

\section{1 - A relação entre o Uno e o múltiplo}

Plotino (205-270), não obstante ser um dos pensadores mais representativos do Ocidente, quase não é conhecido no meio acadêmico brasileiro. Ele deixou sua marca indelével na antropovisão e na mundividência da Idade Média e dos tempos da Renascença e vestígios na filosofia moderna. Dentre as muitas facetas de seu complexo ideário, optamos por tratar, neste trabalho, da processão do múltiplo a partir do Uno, atendo-nos aos tópicos essenciais.

Segundo o autor das Enéadas, do Uno procedem todas as coisas. Como e por que se dá essa processão? Trata-se de duas indagações de ordem metafísica, às quais não é fácil responder. Tentaremos, neste breve estudo, iluminar um pouco 0 caminho, na selva selvaggia do ideário plotiniano, que já deu azo a interpretações variadas e contraditórias.

* Docente da PUCRS e da UNISINOS

\begin{tabular}{|l|l|l|l|l|l|}
\hline VERITAS & Porto Alegre & v. 40 & $\mathrm{n}^{2} 158$ & Junho 1995 & p. 157-164 \\
\hline
\end{tabular}


O próprio Plotino inquire por que o Uno não permaneceu na sua solidão, mas deu origem a tão grande multiplicidade de entes. ${ }^{1}$ A solução por ele apresentada é original, conquanto baseada em filósofos anteriores, e constitui um hápax legómenon.

\section{1 - O que é o Uno?}

Explicitamente, Plotino não dá ao Uno (tò hèn pánta) o nome de Deus. Talvez deva-se isso ao fato de ter tomado conhecimento do judaísmo, na escola de Amônio Sakkas, e do texto do Êxodo 3, 14, onde Deus se apresenta simplesmente como "Sou o que é". Somente pelo tetragrama Jhwh, o povo eleito ousava designar o Altíssimo, expressando, assim, a essência divina. Do mesmo modo, Plotino, com tò hén, quer significar o Super-Ser, isto é, aquele que é o ser em plenitude.

Apelando à experiência religiosa, Plotino soube captar o mistério do divino em si próprio e no mundo. ${ }^{2}$ Soube intuir Deus e vivenciá-lo como nenhum outro filósofo da antigüidade. Assim sendo, não nos parece defensável a idéia de que o Uno plotiniano represente meramente um conceito universal, um metaconceito abstrato, lógico, indeterminado, como o querem Fraile/Urdanoz. Plotino tem o Uno como causa fundante de todas as coisas. ${ }^{3} \mathrm{O}$ único objetivo da vida de Plotino era unir-se ao Uno. Uma nostalgia insopitável do Princípio sem princípio impulsionava-o para a hénosis ${ }^{4}$ pelo êxtase. ${ }^{5}$ Ora, pode alguém unir-se extaticamente a um conceito abstrato? Impossivel. Portanto, a hénosis constitui verdadeira união mística com o Super-Ser, com o Super-Bem, com a Super-Beleza, numa palavra, Deus, que é mistério. ${ }^{6}$

\section{2 - Metáforas relativas ao Uno e à multiplicidade}

Em vez de dar explicações de cunho rigorosamente lógico, Plotino procurou, mediante imagens ou metáforas, ${ }^{7}$ ilustrar como do Uno transcendente, perfeito, infinito, eterno, provém a multiplicidade. Compara o Uno a) com o fogo que emana calor, com a neve que espalha o frio, a substância odorifera que exala o perfume, o

1 Enéadas, $V, 1,6$.

2 PORFÍRIO, Vita Plotini, 2,26-27. "La fin et le but, c'était por lui l'union intime avec le Dieu qui est au-dessus de toutes choses" (Ibidem, 23, 15-16).

3 Enéadas, V, 3, 12.

4 "Il concetto di henosis denomina un processo, un evento e una experienza del pensiero e della coscienza in cui questa si supera e insieme realizza la sua massima possibilità. (...) Nell'autosuperamento la coscienza pensante tende soltanto 'al fondamento', senza tuttavia dissolversi" (BEIERWALTES, Wemer, Pensare L'Uno, Milano: Vita e Pensiero, 1991, p. 116.)

5 Segundo PORFÍRIO, quatro vezes, em sua vida, Plotino atingiu esse estado inefável (êxtase). Cf. Vita Plotini, 23, 16-17.

6 Cf. BEIERWALTES, op. cit., p. 117-120.

7 'L'emploi et le goût des images chez Plotin ont sans doute leur raison dans le caractère même de sa doctrine; les réalités suprêmes, vers lesquelles il conduit l'âme, l'Un et l'Intelligence, ne peuvent être connues que par une intuition immédiate et un contact ineffable; ce sont des réalités proprement inexprimables. Le langage ne peut donc s'en rapprocher qu'en employant des images" (PLOTIN, Ennéades v. I. Texte établi et traduit par Émile BRÉHIER, Introduction, p. XXXV. Paris: Société d'Édition "Les Belles Lettres", troisième édition, 1960.) 
ser vivo que gera outros seres vivos; ${ }^{8}$ b) com a luz que irradia de uma fonte luminosa sem se esgotar jamais; ${ }^{9}$ com a fonte de água inexaurivel, formadora de rios; ${ }^{10}$ com circulos concêntricos. ${ }^{11}$

Por causa dessas imagens, Plotino foi tachado de emanatista, de panteísta e monista. Será que não é possível outra interpretação?

\section{a) Emanatismo?}

A tradução da palavra grega éklampsis ou éklapsis, do verbo eklámpein, não é emanar, stricto sensu, mas espargir luz, irradiar luminosidade. Plotino usa esses termos em sentido figurativo, como também o faz com o verbo aporréou e o substantivo próodos. Conseqüentemente, não se pode dizer que ele seja emanatista. ${ }^{12}$ Plotino distingue entre originante e originado, entre causa e efeito. ${ }^{13}$ Damos, pois, razão a Giovanni Reale, quando diz: "Orbene, di 'emanazione' Plotino parla solo nelle sue immagini, mentre la sua dottrina ne è la negazione". ${ }^{14}$ Concordamos, também, com o mesmo autor, quando justifica a sua asserção: aa) as hipóstases sucessivas (isto é, as instâncias mediadoras) do Uno não são de fato um fluxo da substância do Uno; bb) em conseqüência, não são a substância do Uno despotenciada; cC) não derivam do Uno por mera necessidade natural (física). ${ }^{15}$

Realmente, o que provém do Uno não se identifica com a sua substância, mas é apenas efeito de sua causalidade. Ele é arché, aition, enérgeia, dýnamis, influenciador causal ativo na produção dos seres.

\section{b) Panteísmo?}

Não se logra afirmar, igualmente, que Plotino é panteísta, porquanto "o Uno é todas as coisas e nenhuma delas, pois o princípio de todas as coisas não é todas as coisas.$^{16}$

8 Enéadas, V, 1,6.

9 Ibidem, IV, 3,17.

10 Ibidem, II,8,10. A respeito dessa metáfora, observa BRÉHIER: "C'est l'image célèbre d'où le système de Plotin a pris le nom d'émanatisme; image d'ailleurs fort ancienne que l'on retrouve dans le célèbre serment pythagoricien où la tétrade est déclarée 'source de la nature étemelle'. (...) Plotin tenait à l'individualité et était éloigné d'admettre la confusion de tous les êtres en un seul..." (op. cit., v. III, p. 166-167, nota 1).

11 Enéadas, 4,4,3. Na famosa visão da Santíssima Trindade, descrita por DANTE, encontramos uma imagem semelhante: "Ne la profonda e chiara sussistenza/ de l'alto lume parvermi tre giri/ di tre colori e d'una contenenza;/ e l'un da l'altro come iri/ parea reflesso, e' l terzo parea foco/ che quinci e quindi igualmente si spiri" (Paradiso, 33,115-120).

120 que se entende por emanatismo? "(...) nach dem Emanatismus gehen Dinge (teils unmittelbar, teils mittelbar) aus Gottes eigener Substanz hervor, und zwar notwendig, nicht auf Grund des göttlichen Willens" (LEXIKON FÜR THEOLOGIE UND KIRCHE, zweite Auflage, Freiburg: Verlag Herder, 1959, II Band, col. 841). PLOTINO não se enquadra nessa definição, conforme a exposição que estamos fazendo.

13 Em Enéadas, V, 9,6, lemos: "Tò aítion ou tautón tô aitiatô".

14 REALE, Giovanni, Storia della Filosofia antica, nona edizione, Milano: Vita e Pensiero, v. IV, p. 606.

15 Id., Ibid., p. 607.

16 Enéadas, V, 2,1. 
Cabe observar que Plotino não fala explicitamente em criação ex nihilo", ${ }^{17}$ mas também não fala em emanação, em sentido estrito, entendendo-a como depauperamento da fonte originária. Sua doutrina situa-se na processio. ${ }^{18} \mathrm{~A}$ linguagem empregada por Plotino e os conceitos de causa e efeito não permitem falar em panteísmo. É desfeita toda e qualquer dúvida, uma vez que consta com absoluta clareza: "O Uno não está mesclado com o todo, está acima do todo e é causa do todo". ${ }^{19}$ Ora, se não está mesclado com o todo, não é idêntico ao todo (portanto, também não temos monismo).$^{20}$ Se está acima do todo, é transcendente e absoluto; se é causa do todo, este todo é tão-somente efeito. Indubitavelmente, Plotino não teve a intenção de apregoar nem o panteísmo, nem o monismo.

\section{c) Panenteísmo}

Mesmo que Plotino não expresse a noção de criação, ${ }^{21}$ somos pela idéia de que ele é panenteísta, ou seja, o Uno é transcendente e imanente ao todo. ${ }^{22}$ Plotino conhecia o cristianismo ${ }^{23}$ e com ele conviveu em Roma, como antes em Alexandria. Não lhe era estranha, também, a doutrina criacionista, através de seu mestre Amônio Sakkas. ${ }^{24}$ Plotino assevera peremptoriamente: "É preciso que o Uno seja antes de todas as coisas, é preciso que ele replene (dei autò pleroun pánta) e que produza tudo, mas que não seja tudo quanto produz". ${ }^{25}$

\section{d) Um paradoxo}

Deparamo-nos, porém, com um paradoxo: a processão é livre, portanto não-arbitrária nem irracional, e contudo necessária. Livre, porque, sendo a perfeição

17 Leiamos o que diz o citado REALE: "Tuttavia, sbaglierebbe chi ritenesse che il creazionismo (che egli conosceva dalla filosofia giudaica e da quella dello stesso Ammonio) non abbia in alcun modo influito sulla metafisica plotiniana" (op. cit., p. 609).

18 A síntese complexíssima de PLOTINO constitui algo único na história do pensamento humano. A processão forma um todo sui generis que não se enquadra numa só categoria geral. É plotinismo!

19 Enéadas, V, 13,35.

20 Cf. MERLAN, Philip, Dal Platonismo al Neoplatonismo, Milano: Vita e Pensiero, 1990, p. 192, nota 11.

21 "Giustamente è stato quindi di recente rilevato che si deve concludere che "la volontà dell'Uno di essere la sua propria natura è la causa diretta dell'emanazione dalla sua natura' e che, pertanto, in un certo senso 'la creazione è libera, non più e non meno, di quanto sia l'Uno stesso'. Noi prefiriremmo dire che la creazione (la processione) è una necessità che consegue ad un atto di libertà" (REALE, op. cit., p. 526).

22 Aqui cremos valerem as palavras aplicadas por um renomado autor ao lógos de HERÁCLITO: "Nul panthéisme, mais une identité dialectique. Le lógos est le tout, mais le tout est l'Un qui transcende le cosmos, immanent, et parce qu'immanent, transcendant. C'est ainsi que la vie transcende les êtres vivants, auxquels elle est pourtant immanente, la vie qui est la totalité des vivants, sans être pour autant leur somme" (JEANNIËRE, Abel, Héraclite, troisième édition revue et augmentée, Paris: Aubier, 1985, p. 57).

23 Cf. GLSON, Étienne, L'Esprit de la Philosophie Médiévale, deuxième édition, Paris: Librairie Philosophique J. Vrin, 1948, p. 163, nota 2.

24 "(Ma) che Ammonio non solo potesse, ma dovesse conoscere la dottrina della creazione è fuori dubbio, dato che nacque e fu educato in una famiglia cristiana e dato che in Alessandria già con Filone la dottrina aveva avuto larga risonanza" (REALE, op. cit., p. 468).

25

Enéadas, III, 9,4,7. 
suma, o Uno só pode querer (tem, pois, volição) ${ }^{26}$ transfundir-se naquilo que produz e tornar partícipe de si o que produz de sua superabundância. ${ }^{27}$ Ao Uno podemos aplicar o axioma: "Bonum est diffusivum sui". Essa "difusibilidade" às diversas hipóstases ${ }^{28}$ ninguém logra detê-la. É uma potência ativa, dynamis (virtus), capaz de permanecer em si mesma e, ao mesmo tempo, de "sair fora de $\mathrm{si}^{4}{ }^{29}$ Assim, o Uno, pelo assim dizer, sente-se "obrigado" a comunicar, por processão, a sua própria bondade e fazer as coisas participantes de sua perfeição. Teríamos, então, a inversão do axioma da filosofia escolástica, ou seja, em vez de dizermos "agere sequitur esse", deveriamos dizer "esse sequitur agere". "Como poderia permanecer em si o perfeitíssimo e primeiro Bem, como se fosse avaro de si mesmo ou impotente, Ele que é a potência de todas as coisas?" ${ }^{30}$

A potência (dýnamis tôn pántoun) não significa outra coisa do que a sua unidade implicativa, que tende à explicatio. Por outra, no Uno está, dada a sua potência ativa, o ainda-não-diferente, a ainda-não-alteridade. ${ }^{31}$ Ele é a forma (ato aristotélico) mais rica e mais plena, numa palavra, é a causa exemplar. Dessa implicatio os entes são explicatio. Antecipa-se, nesta linguagem, a do Cusano. Dessarte, Plotino nega a identidade entre o Uno e a alteridade, afirma a distinção e, ao mesmo passo, releva a dissociação entre a alteridade e o Uno.

Sintetizemos esta parte. Tal como da fonte necessariamente brota a água e do fogo deriva necessariamente o calor, assim do Uno necessariamente procede a multiplicidade dos entes, os quais são diferentes dele. ${ }^{32}$ Não há identidade entre o Uno e o múltiplo, mas distinção como entre causa e efeito. ${ }^{33} \mathrm{O}$ Uno, como causa, não sofre alteração em sua unidade e simplicidade, mas sempre permanece imutável. $^{34}$ Os seres derivados do Uno constituem uma imagem ou perfeição da causa incausada. Porém, quanto mais distantes se acham dela, menor é a sua beleza e maior a sua composição em partes.

\section{2 - A processão plotiniana}

Tendo visto, até aqui, o porquê da processão, consideremos brevemente o modo como ela se dá.

26 Cf. nota 21, supra. "Pois o Uno não age sem querer, senão que seus atos são de certa maneira sua essência, sua vontade e essência são a mesma coisa" (Enéadas, VI, 8,13). "Onipotência absolutamente dona de si mesma, que é aquilo que quer, projeta sobre os seres o que quer" (Ibidem, VI, 8,9).

27 "Se deve existir algo absolutamente suficiente a si mesmo, deve ser o Uno, que existe só de maneira tal que, nem com respeito a si mesmo, nem com respeito a outro, se ache necessitado de nada. Pois não requer nada mais para ser, nem para ser bem, nem para seu próprio fundamento. (...) Por isso, para o Uno não há coisa boa nem vontade de algo, senão que ele é o Bem transcendente, e é um bem não para si mesmo, senão para os outros, se existe algo que possa participar dele" (Ibidem, VI, 8,9).

28 Enéadas, IV, 1,3; V, 2,18; VI, 1,6.

29 Ibidem, V, 7,8.

30 Enéadas, V, 4,1.

31 Ibidem, V, 15,31.

32 Ibidem, V, 2.

33 Ibidem, V, 9,6 e V, 2,1.

34 Ibidem, V, 8,6. 
Tal como o fundador da Academia, Plotino separa o ser em duas esferas: a supra-sensivel e a sensivel. Na primeira, situam-se as hipóstases por processão (próodos, éklapsis ou perilampsis). Essa "descida" podemos também denominá-la katábasis, à qual corresponde, por via dialética, a volta ascendente do múltiplo ao Uno. É a epistrophé ou anagogé. Sem deturpar o sentido dessas palavras, cabe também anábasis. O múltiplo inclui a esfera do sensivel.

Vejamos o esquema, a arquitetura ou a "paisagem metafísica" de Plotino.

\section{1 - A triade plotiniana}

\section{a) O Uno - primeira hipóstase}

Em primeiro lugar, está o Uno, a forma mais rica (ato puro), a potência ativa de todas as formas na esfera da alteridade. É fonte e fim último de todos os entes e a todos anima. ${ }^{35}$ Ao Uno não podemos aplicar nenhum dos conceitos a nós conhecidos. ${ }^{36}$ Dele apenas se tem conhecimento apofático. A sua existência é evidente, porque, existindo o múltiplo, necessariamente existe o Uno. ${ }^{37}$ Ele é ilimitado e causa total de toda limitação. Distingue-se nele dupla atividade: a interna, que faz 0 Uno ser o que é, e a dynamis geradora da qual resulta a alteridade ou a multiplicidade. $^{38}$

\section{b) A Inteligência - segunda hipóstase}

Do Uno procede a Inteligência (Lógos ou Nous), a qual é a imagem eterna e infinita do Uno. ${ }^{39}$ Ela não tem a unidade perfeita deste, pois na Inteligência há dois momentos distinguíveis: de uma parte, contempla o Uno e, de outra parte, contempla a si mesma, desde toda a eternidade. ${ }^{40}$ O Nous é cognoscente e conhecido, contemplante e contemplado. Como Inteligência e inteligivel, súmula de todas as idéias (kósmos noetós), vê a si mesma como relação e como múltipla. Dessarte, ela é hèn kaì pollá.

\section{c) A Alma universal - terceira hipóstase}

Do poder criador da Inteligência, procede a terceira hipóstase: a Alma universal (psyché). Nela também se verifica uma dualidade: a intelectiva, voltada para 0 Nous, do qual procede, e a sensitiva, que informa os seres corpóreos. ${ }^{41}$ A psyché conhece o kósmos noetós. Trata-se de uma atividade ad intra. Mas também ad

Ibidem, III, 8,8.

"Der negative Weg im Denken des Einen den er verfolgt, macht ihn (Plotin) so zum Vater der negativen Theologie, zum Eröffner der sogenannten via negativa" (GADAMER, Hans-Georg. Griechische Philosophie, Tübingen (J. C. B. Mohr (Paul Siebeck), 1991, Band 7, p. 412-413).

Enéadas, V, 3,12 e I, 9,17.

Ibidem, V, 2.

Ibidem, III, 8,10; V, 1,7.

Ibidem, V, 1,4

Ibidem, III, 8,3.

Ibidem, VI, 7,6. 
extra se estende a sua ação, por meio da comunicação com a matéria, na qual a psyché se "multiplica" em todos os entes particulares do mundo sensivel, sem dividir-se. ${ }^{43}$ Em outras palavras, a Alma universal não está no mundo, mas este está naquela. Nela, estão todas as matrizes (lógoi spermatikoil) de todos os seres; portanto, ela é como que uma coincidência dos opostos (coincidentia oppositorum). As razões seminais constituem o princípio da diversidade e da variedade dos seres singulares. Dela procedem as almas e todas as formas dos seres sensíveis, desde a planta até o homem, tudo constituindo uma admirável harmonia e beleza. A função da Alma universal é produzir, ordenar e governar o mundo sensível. Se ficamos embevecidos com a harmonia no mundo, é porque esta tem sua causa na Inteligência. ${ }^{44}$ À maneira dos estóicos, Plotino professa que tudo forma uma sympátheia tôn hóloun. ${ }^{45} \mathrm{~A}$ ordem do todo não sofre desfiguramento pelo mal, ${ }^{46}$ mas, antes, ele tem uma função positiva. ${ }^{47}$

O Uno, o Nous e a Alma universal formam a chamada trindade plotiniana. ${ }^{48}$

Aqui terminam as hipóstases do mundo inteligivel e incorpóreo. As hipóstases em causa são realmente universo. Entre elas, não cessa jamais a continuidade relacional por processão (emanação), iluminação. Não cessa a unidade, apesar das diferenças; não cessa a transcendência, apesar da imanência; nem cessa a imanência, apesar da transcendência. Pode dizer-se que o Uno é Ungrund, Urgrund e $A b$ grund.

\section{2 - O mundo sensivel e a matéria}

A esfera do mundo sensivel (kósmos aísthetos) deve sua origem à união da alma sensitiva da Alma universal com a matéria. Aqui, o papel da Alma universal reveste-se de enorme importância, como no-lo explica o próprio Plotino: "A Alma

43 Ibidem, VI, 1,2 e VI, 7,2.

44 Ibidem, III, 1,6. PLOTINO, pelo assim dizer, antecipou-se à Idade Média, época em que a natureza era considerada como um livro em que se espelhava a sabedoria de Deus. Basta citar ALANO DE LILLE: "Omnis mundi creatura/Quasi liber et pictura/Nobis est et speculum" (apud CURTIUS, Emst Robert, Europäische Literatur und Lateinisches Mittelalter, 6. Auflage, Bem und München, Francke Verlag, 1967, p. 323).

45 Enéadas, IV, 4,41.

46 "É absurdo queixar-se das partes, com relação ao todo; as partes devem ser examinadas com relação ao todo, para ver se elas lhe convêm e lhe estão ajustadas; é mister ver o conjunto, sem dar importância aos mínimos detalhes" (Ibidem, II, 2,3).

47 "Il mondo empirico è cosí insieme rappresentazione o manifestazione della bellezza intelligibile: come opera del suo creatore esso è 'un Tutto somamente bello, che basta a se stesso (ossia perfetto), che concorda amichevolmente con se stesso e con le sue parti, sia quelle che lo sono di meno, poichè queste gli sono ugalmente legate' (III, 2,3)" (BEIERWALTES, op. cit., p. 87). E o mesmo autor acrescenta: "Proprio la tentazione che viene dalla materia, la sua apparenza incantatrice nella sfera dell'agire sta in una sicura discrepanza con la concezione di un mondo, che è - per dirla con Agostino - etiam cum sinistra parte perfecta (detto della universitas, la cui perfectio è Dio: Solil. II, 2) ${ }^{n}$ (Idem, Ibidem, p. 87 e nota 40).

48 "Las tres hipóstasis árquicas, el Uno, la Inteligencia y el Alma, es lo que se ha llamado la trinidad plotiniana. Son tres hipótasis distintas, inferiores unas a otras y no consubstanciales ni idénticas en esencia. Vienen a responder a la trinidad arriana, pero son completamente distintas de la Trinidad del dogma católico" (FRAIIE/URDANOZ, Historia de la Filosofia, cuarta edición, Madrid: BAC, 1976, v. I, p. 733 , nota 61 ). 
universal é a que produziu todos os animais sobre a Terra, no ar e no mar, bem como os astros divinos e o céu imenso, insuflando-lhes seu espírito. ${ }^{149}$

Por último, temos a matéria, que é eterna ${ }^{50}$ representando a limitação e a imperfeição e constituindo o princípio do mal. Ela é como que o horizonte mais longínquo em que a luz irradiadora do Uno se confunde com o lusco-fusco. Para Plotino, princípio do mal não tem, em absoluto, o sentido gnóstico-maniqueísta. Significa, simplesmente, que a matéria representa a última possibilidade de algo existir. Para além dos limites dela, não há mais processão nenhuma.

Terminada a processão descendente, ainda não está tudo concluído. Tudo quanto provém do Uno há que percorrer o caminho de retorno. ${ }^{51} \mathrm{~A}$ exigência precipua da filosofia de Plotino é a homoiosis com Deus. ${ }^{52}$ Disso trataremos em outro estudo.

Concluamos. Fundamentados em textos de Plotino e em interpretações de autores de peso, consignamos, ainda que brevemente, uma possivel leitura do autor das Enéadas, no que tange à processão.

Por ser uma figura plurifacetada, Plotino é objeto das mais variadas hermenêuticas: monista panteísta continuam a considerá-lo alguns; outros honram-no com o título de panenteísta e criacionista.

Plotino buscou explicar a unidade, a unicidade, a transcendência e a imanência do Uno, como arché. Super-Ser, inefável, causa de todas as coisas, o Uno é "ser" no pleno sentido da palavia e não uma indeterminação de um conceito universalíssimo. Do contrário, como seria possivel a hénosis?

A crescente multiplicidade de entes, na sucessão das hipóstases e das esferas inferiores, dependentes, em última análise, do Uno, indica não apenas um número cada vez maior de entes presentes, mas também uma crescente limitação (determinação), até chegar-se ao mínimo de unidade na matéria, princípio do mal.

Permanecem, no entanto, cruciais dificuldades, como: a derivação das hipóstases supra-sensiveis, a partir do Uno, o qual é causa de tudo, não sendo um processo que sucede no espaço e no tempo, comparável, pois, antes a uma implicatio lógica do que uma relação causal, pode ser interpretada como causalidade eficiente? Na visão plotiniana, pode-se falar em contingência dos seres? Os alemães aplicam à metafísica de Plotino o termo Ableitungssystem. Mas este implica, de certo modo, um monismo articulado e compromete a transcendência do Uno.

$\mathrm{O}$ que acabamos de colocar não é para contradizer a posição assumida neste trabalho, mas visa a mostrar a diversidade de paradigmas para estudo, oferecidos pela obra de Plotino. 